\title{
Effect of Salbutamol on Respiratory Mechanics in Bronchiolitis
}

\author{
DANIEL M. HUGHES, PETER N. LESOUËF, AND LOUIS I. LANDAU \\ Department of Thoracic Medicine, Royal Children's Hospital, Melbourne, Victoria, Australia
}

\begin{abstract}
The effect of inhaled bronchodilators in bronchiolitis has been difficult to evaluate due to problems with techniques for assessing respiratory function in infants. Two new techniques were used to assess the response to inhaled salbutamol in 17 infants with bronchiolitis. With one technique, expiratory flow, volume, and airway occlusion pressure were measured and used to derive compliance (Crs) and conductance (Grs) of the respiratory system from a passive expiration induced by a brief end-inspiratory airway occlusion. With the other technique, the maximum flow at functional residual capacity (V maxFRC) was measured from a partial maximum expiratory flow-volume curve generated by external chest compression. For the group, there was no change in compliance or conductance after salbutamol, but salbutamol caused a fall in maximum flow at functional residual capacity $(p<0.01)$ and in the time constant of tidal expiration $(p<0.01)$. The decrease in maximum flow at functional residual capacity with salbutamol is consistent with increased airway collapse on forced expiration. The decrease in tidal time constant suggests that the drug decreases expiratory braking. Presence of such braking activity may be an important strategy for maintaining lung volume. In summary, salbutamol failed to produce a beneficial effect on airways in bronchiolitis, but did produce changes in expiration which may be harmful in some infants. (Pediatr Res 22: 83-86, 1987)
\end{abstract}

\section{Abbreviations}

Pao, airway pressure

FRC, functional residual capacity

VmaxFRC, maximum flow at FRC

$\mathrm{Tt}$, time constant of tidal expiration

Trs, time constant of the respiratory system

Ve, expired volume

Crs, compliance of the respiratory system

Rrs, resistance of the respiratory system

Grs, conductance of the respiratory system

TGV, thoracic gas volume

Inhaled bronchodilators are widely used in many centers in the management of acute viral bronchiolitis. Their use has been encouraged by the observed strong association between bronchiolitis and subsequent asthma (1) and by the clinical similarities of bronchiolitis to infantile asthma. There is little objective evidence to support the use of inhaled bronchodilators in viral bronchiolitis (2); some studies show no response to these agents

Received May 14, 1986; accepted February 13, 1987

Correspondence and reprint requests Dr. P. N. LeSouëf, University Department of Child Health, Princess Margaret Hospital for Children, G.P.O. Box D184, Perth, Western Australia, 6001 Australia.

D.M.H. is recipient of a McLaughlin Travelling Fellowship, Canada
(3-8), others suggest some response (9-11). This inconsistency may be due to the lack of a reliable assessment of peripheral airways function $(1-12)$.

We have used the passive $(13,14)$ and forced $(15,16)$ expiratory flow-volume maneuvers to assess the effect of inhaled salbutamol on respiratory mechanics in 17 infants with acute viral bronchiolitis. The passive technique has the advantage of allowing compliance and conductance to be measured in the absence of artifacts due to both respiratory muscle activity (13) and the frequency dependence of the two variables $(17,18)$. The forced technique reflects small airway function (15) which has not previously been investigated in bronchiolitis.

\section{SUBJECTS AND METHODS}

The subjects were chosen from infants admitted to the Royal Children's Hospital, Melbourne, during the 1983 winter bronchiolitis season. At the time of study, all infants exhibited the typical clinical pattern of bronchiolitis, with tachypnea, hyperinflation, expiratory wheeze, and/or inspiratory crepitations on auscultation. Only infants with nasopharyngeal specimens positive for respiratory syncytial virus antigen were studied.

Seventeen infants were studied; ten were male and seven female. They were studied at a mean of 3.6 days (range 1-14) after admission to hospital. Mean duration of hospital admission was 5.7 days (range 3-17 days). Mean age was 20.6 wk (range 8$50 \mathrm{wk}$ ) and mean weight when studied was $6.5 \mathrm{~kg}$ (range 3.8 9.5 ). Mean weight at birth was $3.2 \mathrm{~kg}$. All but two of the infants were born at full-term. The two born preterm were 25 and 34 wk gestation with birth weights of 0.8 and $2.5 \mathrm{~kg}$, respectively. Both these infants had been in apparently good health prior to this illness. Birth weight of the full-term infants ranged from 2.2 to $3.9 \mathrm{~kg}$.

The study was performed with the approval of the Hospital Medical Ethics Committee and informed consent was given by the attending parent for each subject. Subjects were studied in the recovery phase of their illness soon after they no longer required supplementary oxygen. They were fasted for $4 \mathrm{~h}$ then sedated with chloral hydrate $(50 \mathrm{mg} / \mathrm{kg})$ orally, accompanied by either bottle or breast feeding. Subjects were studied asleep in the supine position.

For the forced expiratory flow-volume method, the chest and abdomen were compressed using a plastic inflatable cuff with an outer layer of nonexpansile material. The cuff was inflated from a large gas reservoir, equipped with a blow-off valve to prevent excessive pressure. Reservoir pressure was measured using a water-filled manometer while cuff pressure was measured using a Statham P23 transducer. A moulded plastic putty face mask attached to a slide valve was placed over the mouth and nose. The slide valve (13) had three positions: 1) open to the atmosphere; 2) airway occlusion; 3) breathing through a Fleisch "1" pneumotachograph. The pneumotachograph was attached to a Validyne DP-45 differential pressure transducer and a Validyne CD-19 carrier amplifier. Volume was obtained by electronic 
integration. Pao was measured from a port in the slide valve using a Statham P 23 transducer.

To minimize the dead space effect, a catheter inserted into the side of the face mask provided air $(51 / \mathrm{min})$ directly to the infant. This air flow was turned off immediately prior to the performance of each flow-volume maneuver. Flow, volume, airway, and cuff pressures were recorded on a chart recorder (Hewlett-Packard no. $7754 \mathrm{~A}$ ) run at 10 or $25 \mathrm{~mm} / \mathrm{s}$ and simultaneously stored on tape (Racal Store 4D). Flow and volume signals were monitored during the study on a Tektronix 5223 digitizing storage oscilloscope. Tape signals were played back following the study at reduced speed onto a Hewlett-Packard 7046A x-y paper plotter.

A series of forced flow-volume maneuvers was performed using gradually increasing cuff pressure until maximum flow was achieved. Cuff pressure required for maximum flow never exceeded $50 \mathrm{~cm}_{2} \mathrm{O}$. Following normal tidal breathing, the cuff was rapidly inflated at end-inspiration and the resulting flowvolume curve recorded. Maximum flow was then measured on the forced curve at the same volume as the end-expiratory lung volume on the tidal curve. By convention, this volume is called FRC and the maximum flow at this volume is $\mathrm{V}$ maxFRC (16). The time constant of $\mathrm{Tt}$ was measured on the breath preceeding the forced expiration. Tt was taken as the inverse to the mean slope of the straight line of best fit (determined by eye) to the downslope of the tidal expiratory flow-volume relationship. This downslope approached linearity in all infants. As $\mathrm{Tt}$ is volume divided by flow, it has the units of time. Tt for a given infant was calculated as the mean $\mathrm{Tt}$ for five breaths, each of which preceded a forced expiration. The mean coefficient of variation for $\mathrm{Tt}$ was $14.8 \%$ (range 3.4-26.2).

Passive respiratory mechanics were measured using the passive expiratory flow-volume method $(13,14)$. With this technique, the airway is briefly occluded at end-inspiration inducing the

Table 1. Pulmonary function data before and after salbutamol nebulization in 17 infants [mean (SD)]

\begin{tabular}{lccc}
\hline & Presalbutamol & Postsalbutamol & $p$ \\
\hline $\mathrm{Crs}\left(\mathrm{ml} \cdot \mathrm{cm} \mathrm{H}_{2} \mathrm{O}^{-1}\right)$ & $6.91(2.29)$ & $6.35(1.44)$ & $\mathrm{NS}$ \\
$\mathrm{Grs}\left(\mathrm{ml} \cdot \mathrm{s}^{-1} \cdot \mathrm{cm}\right.$ & $19.9(7.4)$ & $18.8(6.7)$ & $\mathrm{NS}$ \\
$\left.\quad \mathrm{H}_{2} \mathrm{O}^{-1}\right)$ & & & \\
$\operatorname{Trs}(\mathrm{s})$ & $0.37(0.10)$ & $0.35(0.08)$ & $\mathrm{NS}$ \\
$\dot{\operatorname{VmaxFRC}}\left(\mathrm{ml} \cdot \mathrm{s}^{-1}\right)$ & $81.3(42.5)$ & $60.9(30.5)$ & $<0.01$ \\
$\mathrm{Tt}(\mathrm{s})$ & $0.49(0.16)$ & $0.39(0.08)$ & $<0.01$ \\
\hline
\end{tabular}
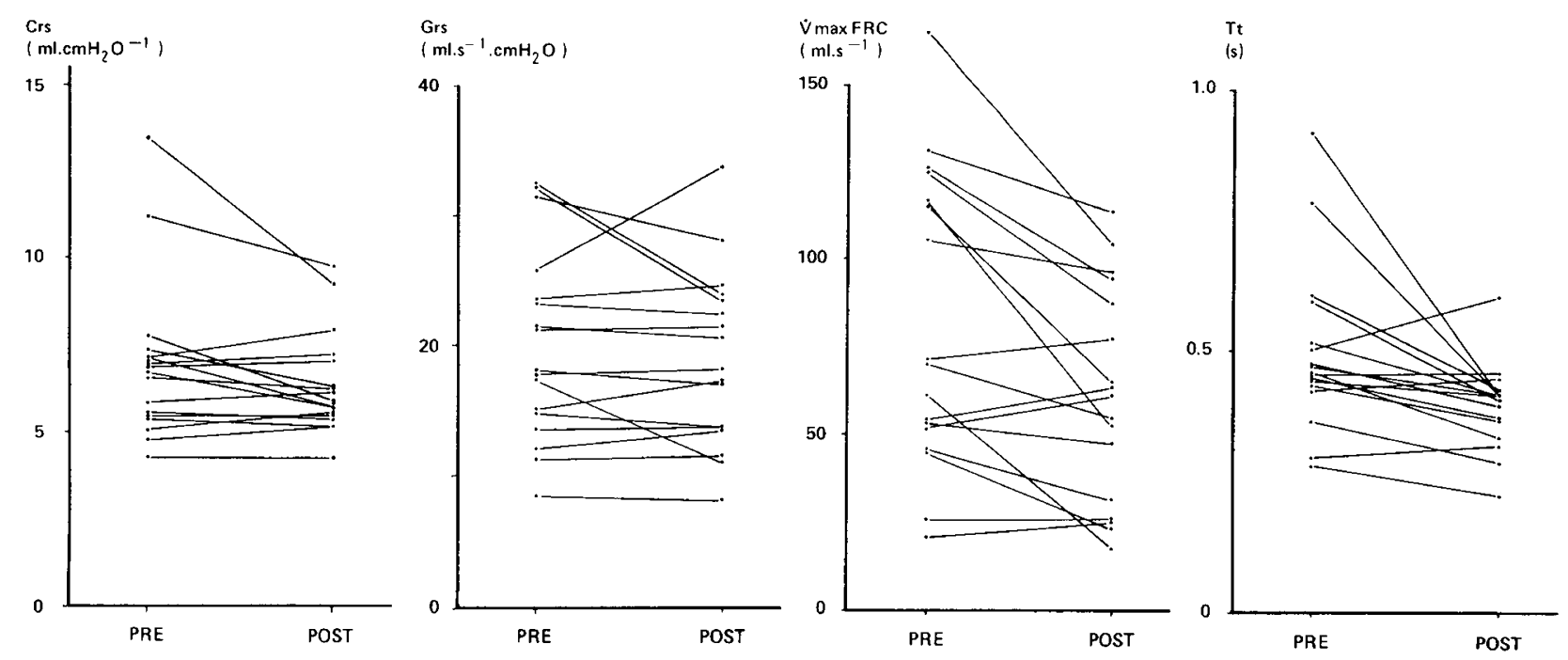

Fig. 1. Crs and Grs of the respiratory system, $\dot{V} \operatorname{maxFRC}$, and the $\mathrm{Tt}$ in each of the 17 subjects before and after salbutamol nebulization. $\dot{V} \operatorname{maxFRC}$ and $\mathrm{Tt}$ decreased after salbutamol $(p<0.01)$. respiratory muscles to relax. Airway occlusion pressure is obtained, and the occlusion is released allowing the infant to expire passively. The flow-volume plot during passive expiration is linear, indicating that the respiratory muscles are relaxed and that both expiratory flow and volume are following a single negative exponential decline (13). The inverse of the downslope of the plot is the passive Trs and by extrapolating this line to the zero flow axis the total passive Ve is available. Extrapolation is necessary because infants inspire before completing a full passive expiration (13). The volume at which the extrapolated line intersects the zero flow axis is the volume in the relaxed system and this volume can be described as passive FRC. The volume at the end of tidal expiration can, therefore, be called dynamic FRC. Crs is Ve divided by Pao and Rrs is Trs by Crs; therefore, Grs is Crs divided by Trs. Crs and Grs were determined for each infant as the mean of five expirations.

The passive and forced expiratory flow-volume maneuvers were performed before and after inhalation during tidal breathing of $0.2 \mathrm{ml}(<5 \mathrm{~kg}$ body wt) or $0.3 \mathrm{ml}(>5 \mathrm{~kg})$ of $0.5 \%$ salbutamol respirator solution made up to $2 \mathrm{ml}$ with normal saline.

The clinical course in the hospital for each subject was reviewed and details were obtained of any previous wheezing episodes as well as a family history of asthma and atopic disease.

Variables measured during passive, forced, and tidal expiration were compared before and after nebulizations using the twotailed paired Student's $t$ test. These variables were also compared between groups subdivided according to history.

\section{RESULTS}

A review of the hospital course following admission showed that $12 / 17(71 \%)$ subjects required supplementary oxygen and $5 / 17(29 \%)$ required intravenous fluids as respiratory distress precluded oral feeding. Four of the $17(24 \%)$ had a history of previous wheezing episodes and 5/17 (29\%) had a family history of asthma in first degree relatives.

Respiratory function data are summarized in Table 1. There was no significant change in compliance, conductance, or passive time constant following salbutamol nebulization. For the group there was a significant fall in maximum flow at FRC $(p<0.01)$ and in $\mathrm{Tt}(p<0.01)$ following salbutamol.

The individual changes of Crs, Grs, VmaxFRC, and Tt following salbutamol are illustrated in Figure 1. There was no significant difference in maximum flow between subjects with and without a family history of asthma or between subjects with and without a previous history of wheezing. 


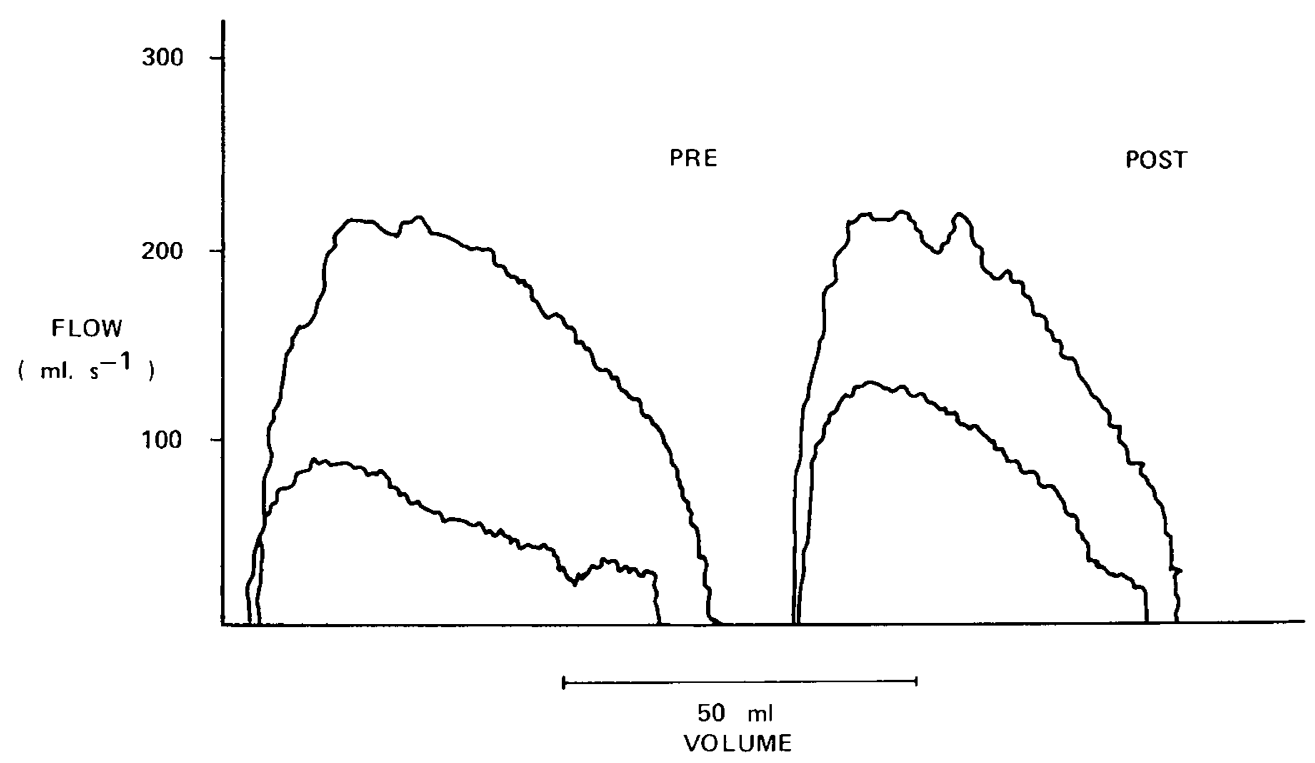

Fig. 2. Forced expiratory flow-volume curve with preceding tidal curve (smaller curve) before and after salbutamol nebulization in one subject. The patient was 9 wk old, weighed $3.8 \mathrm{~kg}$, and was studied 7 days after admission. After salbutamol there is a marked increase in the slope of the tidal expiration (i.e. a decrease in the time constant $\mathrm{Tt}$ ). If the two sets of curves are superimposed using the same point for $\mathrm{FRC}$, flow is the same for the forced curves for the first half of expiration, but flow for the postsalbutamol curve is below the presalbutamol curve for the latter half of expiration.

Figure 2 illustrates an example of maximal expiratory flowvolume curves from one patient before and after salbutamol. With the administration of salbutamol the slope of tidal expiratory flow is increased (the time constant of $\mathrm{Tt}$ is decreased), whereas forced expiratory flow is the same for the first half of expiration but less for the last half of expiration.

\section{DISCUSSION}

The question of whether or not infants with bronchiolitis should be treated with a bronchodilator agent has remained unresolved (2). There are two main reasons for this. The first is that there have been methodologic problems in making measurements of respiratory function in infants. The techniques commonly employed, body plethsmography $(3,8,11,12)$, esophageal balloon manometry $(3,9,12)$, and respiratory conductance by the forced oscillation method $(5,10,11)$, are affected by airway closure and large airway (including nasal) patency and do not specifically assess lower airway function. Silverman (2) recently pointed out that the forced flow-volume method could provide the necessary sensitivity for measuring small airway patency and therefore should be a more appropriate technique for assessing bronchodilator response in bronchiolitis.

The second reason the question remains unresolved is that controlled studies on the use of bronchodilators in bronchiolitis have not shown a significant bronchodilator (4-8) response. A single dose of a nebulized sympathomimetic agent failed to produce a group response in several studies $(3-5,7-9)$ and nebulized ipratropium bromide, although initially thought to induce bronchodilation $(9,11)$, failed to do so in a double-blind trial (6). However, all these studies employed techniques which do not adequately reflect small airway caliber. Were the techniques so insensitive that a response was missed, or was there no response to measure?

In the current study, we have found that salbutamol has no beneficial effect on basic respiratory function, but does cause a significant alteration in the pattern of breathing. For the group there was no significant change in compliance or conductance with salbutamol (Table 1, Fig. 1). This is in line with findings from previous studies in which dynamic resistance (4), airway conductance (8), and total resistance (9) were unaffected by sympathomimetic agents.

We also found that salbutamol caused a fall in forced expiratory flow at FRC. A similar observation has been made in a preliminary study by Spier et al. (19) who studied wheezy infants and noted that salbutamol caused a fall in VmaxFRC but no change in lung resistance (measured by the forced oscillatory technique).

As expiratory flow is volume dependent, it is important that expiratory flow be measured at comparable lung volumes. Thus, the fall in VmaxFRC after salbutamol could either reflect a decrease in caliber of small airways or a reduction in lung volume. Plethysmograhic determination of lung volume was not undertaken in this study, as the technique may be unreliable in the presence of airways obstruction (20). However, there are several lines of evidence suggesting that lung volume did not change significantly after salbutamol. First, TGV was unaffected by salbutamol in two previous studies in similar infants $(8,10)$. Radford (8) investigated 10 infants and found the mean TGV to be $306 \mathrm{ml}$ presalbutamol and $309 \mathrm{ml}$ postsalbutamol. In our department, Soto et al. (10) studied 50 infants with bronchiolitis and also found that there was no effect of salbutamol on TGV. Second, Crs and Grs were not changed by salbutamol in the present study. If obstructed airways were opened up after bronchodilator therapy, hyperinflation would be expected to diminish the $\mathrm{Crs}$ and Grs would increase. Third, an additional comparison was made using passive FRC as a volume landmark for the measurement of maximum expiratory flow. $\dot{V}$ maxFRC is usually measured using dynamic FRC (the lung volume at the end of a tidal expiration) as a volume landmark; if dynamic FRC changed after salbutamol, $\dot{V}$ maxFRC could be measured at a different lung volume. Passive FRC could be expected to be a more reliable volume landmark, as it should only be affected by a change in elasticity. As elasticity (i.e. compliance) did not change after salbutamol, passive FRC would not be expected to change. Therefore maximum expiratory flows were compared at the same volume above passive FRC for pre- and postsalbutamol expirations. This was done as follows. From superimposed tidal and passive flow-volume loops the difference between dynamic FRC and passive FRC can be easily derived (13); this difference was obtained both before and after salbutamol in each infant. For 
the study group, there was a small decrease [mean $2.6 \mathrm{ml}$ (SD 2.9) $p<0.01]$ in the difference between dynamic and passive FRCs after salbutamol. A correction was now made in each infant to account for the change in dynamic FRC (passive FRC was assumed, using the above rationale, to be unchanged by salbutamol). This correction was made by comparing the prenebulization VmaxFRC (measured, as usual, at dynamic FRC) with maximum flow after salbutamol measured at the same volume above passive FRC as had been the case in the presalbutamol curves. Applying this correction, flows post salbutamol remained lower than those presalbutamol $(p<0.02)$.

As the fall in maximum expiratory flow after salbutamol does not appear to be to result from a decrease in lung volume, it may be due to a reduction in either airway caliber or airway stiffness. The latter situation has been implicated in cystic fibrosis; the decrease in expiratory flow in children with cystic fibrosis after $\beta-2$ sympathomimetic therapy (21) was thought to result from airway compression secondary to reduced bronchomotor tone. Perhaps in infants, airway smooth muscle has a more important function holding the airway open than in altering its diameter.

We also found that salbutamol induced a change in the pattern of tidal breathing: the tidal expiratory time constant was decreased by salbutamol (Table 1, Fig. 1). The likely cause is a change in the caliber of the upper airway. We suggest that glottic narrowing to brake expiration may be used by an infant with bronchiolitis as a strategy for maintaining a relatively high endexpiratory volume, and that this strategy may be lost after salbutamol administration. This concept is supported by our data, as the change in tidal time constant could not be due to a change in lung physiology; passive respiratory mechanics were unaltered (Table 1, Fig. 1) and forced maximum expiratory flow fell with salbutamol (Table 1, Figs. 1 and 2). Furthermore, dynamic FRC was closer to passive FRC after salbutamol. Although this effect of salbutamol was small, the finding is consistent with a decrease in expiratory braking. As infants with bronchiolitis could achieve better expiratory flow by being hyperinflated, a loss of laryngeal expiratory braking might be hazardous for some infants.

The decreased tidal expiratory time constant after salbutamol has important implications. First, the conventional method of measuring conductance in infants, including the measurement of airway conductance by plethysmography $(2,8,11,12)$, the esophageal balloon technique $(3,9,12)$, and the forced oscillation method $(5,7,10,11,19)$, are performed during tidal breathing, so any change in upper airway caliber will be recorded as a change in conductance. Thus the "improvement" in lung function seen in some subjects in some studies using these techniques (9-11) could be explained by a change in laryngeal caliber if measurements are made during expiration. However, this problem may not be present if measurements are confined to inspiration provided inspiratory laryngeal caliber is unchanged by salbutamol. Second, the infant with the postsalbutamol pattern of expiration might appear to be breathing more easily, despite no improvement in lung function. Our finding therefore raises new doubts about both the ability of conventional techniques to measure bronchodilator response accurately and the reliability of assessing bronchodilator response in infants by clinical scores based on observation.

Many infants with acute viral bronchiolitis have significant respiratory distress and hypoxemia (22-24). The handling and attendant distress that may be created during the administration of a nebulized bronchodilator to these infants in the acute phase of their illness as well as the lack of physiologic evidence of its effectiveness do not support the routine use of this form of therapy.

Acknowledgment. The authors thank Mrs. Susan Conlan for secretarial services.

\section{REFERENCES}

1. Rooney CI, Williams HF 1981 The relationship between proven viral bronchiolitis and subsequent wheezing. $J$ Pediatr 79:744-747

2. Silverman M 1984 Bronchodilators for wheezy infants? Arch Dis Child 59:8487

3. Phelan PD, Williams HE, Freeman M 1968 The disturbances of ventilation in acute viral bronchiolitis. Aust Paediatr J 4;96-104

4. Phelan PD, Williams HE 1969 Sympathomimetic drugs in acute viral bronchiolitis. Their effect on pulmonary resistance. Pediatrics 44:493-497

5. Rutter N, Milner AD, Hiller EJ 1975 Effect of bronchodilators on respiratory resistance in infants and young children with bronchiolitis and wheezy bronchitis. Arch Dis Child 50:719-722

6. Henry RL, Milner AD, Stokes GM 1983 Ineffectiveness of ipratropium bromide in acute bronchiolitis. Arch Dis Child 58:925-926

7. Lenney W, Milner AD 1978 Alpha and beta adrenergic stimulants in bronchiolitis and wheezy bronchitis in children under 18 months of age. Arch Dis Chil 53:707-709

8. Radford M 1975 Effect of salbutamol in infants with wheezy bronchitis Arch Dis Child 50:535-538

9. Stokes GM, Milner AD, Hodges IGC, Henry RL, Elphick MC 1983 Nebulized therapy in acute severe bronchiolitis in infancy. Arch Dis Child 58:279-283

10. Soto M, Sly PD, Uren E, Taussig LM, Landau LI 1985 Bronchodilator response in acute viral bronchiolitis. Pediatr Pulmonol 2:85-90

11. Hodges IGC, Groggin RC, Milner AD, Stokes GM 1981 Bronchodilator effect of inhaled ipratropium bromide in wheezy toddlers. Arch Dis Child 56:729732

12. Krieger I 1964 Mechanics of respiration in bronchiolitis. Pediatrics 33:45-54

13. LeSouëf PN, England SJ, Bryan AC 1984 Passive respiratory mechanics in newborns and children. Am Rev Respir Dis 129:552-556

14. LeSouef PN, England SJ, Bryan AC 1984 Total resistance of the respiratory system in preterm infants with and without an endotracheal tube. $J$ Pediatr 104:108-111

15. Adler SM, Wohl ME 1978 Flow-volume relationship at low lung volumes in healthy term newborn infants. Pediatrics 61:636-640

16. Taussig LM, Landau LI, Godfrey S, Arad T 1982 Determinants of forced expiratory flows in newborn infants. J Appl Physiol 53:1220-1227

17. Otis AB, McKerrow CB, Bartlett RA, Mead J, McIlroy MB, Selverstone NJ Radford EP 1956 Mechanical factors in distribution of pulmonary ventilation. J Appl Physiol 8:427-442

18. Stanescu D, Moavero NE, Veriter C, Brosseur L 1979 Frequency dependence of respiratory resistance in healthy children. J Appl Physiol 47:268-272

19. Spier S, Lapierre JG, Lamarre A 1985 Response to salbutamol during a 1st or 2nd episode of wheezing in infancy. Am Rev Respir Dis 131:A259

20. Helms P 1982 Problems with plethysmographic estimation of lung volume in infants and young children. J Appl Physiol 53:698-702

21. Landau LI, Phelan PD 1973 The spectrum of cystic fibrosis. A study of pulmonary mechanics in 46 patients. Am Rev Respir Dis 108:593-602

22. Reynolds EOR 1963 Arterial blood gas tensions in acute disease of lower respiratory tract in infancy. Br Med J 1:1192

23. Reynolds EOR 1963 The effect of breathing 40 percent oxygen on the arterial blood gas tensions of babies with bronchiolitis. J Pediatr 1963;1 135-1139

24. Reynolds EOR, Cook CD 1963 The treatment of bronchiolitis. J Pediatr 63:1205-1207 